\section{Occupational therapists in Emergency Departments}

\author{
Kirstin James
}

Mrs MacDonald ${ }^{\mathrm{i}}$ was 87 years old and had lived on her own since her husband of 60 years died. She had lived in the same house all her married life and although she had three grown-up children, she did not see them regularly as they lived some distance away. She was not able to leave her house very often and over the last few years she had become increasingly frightened that she would fall outside, especially if the weather was bad and the pavements icy.

Mrs MacDonald had been found lying on the floor that morning by her carer, who came to her home every day to assist her with showering, getting dressed and preparing breakfast. It appeared Mrs MacDonald had fallen during the night, and had been on the floor for some hours. Her carer was unable to help her from the floor, and she was complaining of extreme pain in her shoulder. The carer called 999 for the Ambulance Service, and after assessment by paramedics, she was conveyed to the ED of her local hospital.

Mrs MacDonald was seen within the hour by an ED doctor who noted her history of high BP and diabetes. The doctor suspected, from the pain and swelling, that she had a fracture to her humerus; an X-ray confirmed this. As Mrs MacDonald lived on her own, had been to the ED three times already that year as a consequence of falling and was now unable to use her dominant hand, the doctor deemed an occupational therapy assessment necessary. She was concerned about Mrs MacDonald's ability to care for herself, and indeed, due to the pain she was currently suffering, doubted whether she could even go home at all. She prescribed some pain-relief for Mrs MacDonald, requested that the ED nurse

\footnotetext{
i‘Mrs MacDonald' represents an 'every-woman' rather than an individual, that is, a representative patient to showcase a 'typical' occupational therapy intervention in the ED. As such, informed consent has not been sought.
}

Correspondence to Dr Kirstin James, School of Health, Nursing and Midwifery, University of the West of Scotland, Paisley Campus, High Street, Paisley, Renfrewshire PA1 2BE, UK; kirstin.james@uws.ac.uk provide Mrs MacDonald with a collarand-cuff sling and bleeped (paged) the occupational therapist.

I arrived promptly in the ED, reviewed Mrs MacDonald's ED medical notes and briefly spoke to the doctor. I introduced myself and my role as an occupational therapist to Mrs MacDonald and gained her verbal consent to my intervention. I explained that I was going to work with her and decide if there was any possibility she could be discharged home. Mrs MacDonald was emphatic that she wished to return home, no matter what. She was starting to feel some relief from the pain medication and agreed that she was ready to participate with me.

I began by asking her about her living circumstances, the layout of her home, how many times she had to go up and down her stairs during the day, how often she got out of bed at night, any equipment she had to help her (which included a shower chair and a bed rail) what she could do to care for herself and what she received help from her carer for. I also attempted to gauge what was most important to Mrs MacDonald, what activities she liked to participate in and what she did for leisure. From how Mrs MacDonald was able to participate in the interview and how she was able to give a detailed description of her circumstances, I understood she had no particular challenges from a cognitive perspective.

I then carried out a physical assessment, testing the strength and range of movement of all but her affected (fractured) limbs, before getting Mrs MacDonald to assume a seated position on the ED trolley. It was obvious that Mrs MacDonald was in pain as she attempted to move herself. I called on a nursing colleague to provide assistance in moving Mrs MacDonald from the hospital trolley to a chair, as she had not attempted to stand since her fall that morning and I was concerned about possible hypotension on standing.

Once she was in the chair, I asked her to attempt the 'get-up-go-test' ${ }^{1}$ and I concluded that, despite her pain, Mrs MacDonald could transfer from the chair onto her feet and walk unaided over a distance similar to that she covers within her home.
I then addressed Mrs MacDonald's selfcare skills and reviewed how to care for her fractured arm, how to dress and undress safely and how to take the collar-and-cuff on and off. Mrs MacDonald had a carer in the morning, but the carer did not return again all day. Mrs MacDonald again reiterated that she wanted to go home and felt she would manage if her carer's visits could be increased to three times a day to provide assistance with making food at lunchtime and preparing for bed at night.

Increasing the frequency of her caregiver visits would require a referral to the local social services department and this might take some days to organise. However, I offered to call in the 'crisis care team' to assist her to return safely home and provide the urgent care support she required. Although she would not know the new carers, Mrs MacDonald agreed.

By this time, three and a half hours had elapsed and the doctor was anxious to know when I would finish my intervention, as it was getting close to the ' $4 \mathrm{~h}$ target' standard. ${ }^{2}$ My ED assessment allowed us to conclude that Mrs MacDonald was safe to be discharged home; however, I would complete a home assessment with Mrs MacDonald later that day. A taxi was promptly organised by the ED team so she could be discharged.

After Mrs MacDonald left the ED, I telephoned the crisis care team to make the referral. They would send carers to help Mrs MacDonald and this would continue until a more permanent care package could be organised. I then filled out paperwork for the social work department so that an increase in carer hours could be scheduled.

Later, that day, I visited Mrs MacDonald at home. Mrs MacDonald was starting to look more comfortable. A carer from crisis care had already visited and was making sure Mrs MacDonald was taking her pain medication on schedule. I was concerned about the number of falls Mrs MacDonald had that year, so I assessed her home and made some suggestions to improve safety. I had brought with me a commode to leave at her bed side so she would not need to walk to the bathroom at night, and gave her information leaflets about community supports and falls prevention. We also discussed attendance at the local day hospital so that Mrs MacDonald could participate in a falls education programme and socialise outside of her home on a regular basis. I also advised Mrs MacDonald that I would assess her needs again when she came 
back to the ED the following week, to attend the fracture clinic.

The following week, Mrs MacDonald came back to her appointment at the ED fracture clinic and I met her there. She described having a 'difficult' week, as she had ongoing pain in her shoulder and was having to adapt to using one hand to carry out all her daily living tasks. However, she felt she was 'over the worst of it' and was positive about her recovery. We decided that she did not require any further occupational therapy at this time, but I left my details with her, so she could make contact by telephone should she need to.

In the UK, as in other parts of the world, occupational therapists have an increasing presence in EDs. ED attendances are often characterised, not by lifethreatening medical emergencies, but by non-emergency situations, for example, relapses in chronic conditions, the consequences of a fall, a breakdown in social care or functional difficulties including a decrease in mobility. Safe discharges back to the community often require an assessment of needs and setting up support systems, in addition to treating medical symptoms. Simply put, 'occupational therapists...help people to do the things they want to do'. 3 They thus provide the safety net that can prevent hospital admission or a return ED visit.

Acknowledgements I thank Dr Susan Kerr, Dr Larissa Kempenaar and Dr Jenny Preston at Glasgow Caledonian University and Dr Derek Jones at Edinburgh University who were my Professional Doctorate supervisors. ${ }^{4}$

Competing interests None declared.

Ethics approval Glasgow Caledonian University.

Provenance and peer review Not commissioned; internally peer reviewed.

Data sharing statement My Professional Doctorate thesis 'The lived experience of Occupational Therapists in Emeregency Departments in Scotland' has been donated to the College of Occupational Therapists library.

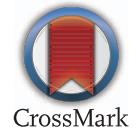

To cite James K. Emerg Med J 2016;33:442-443.

Received 4 November 2015

Accepted 14 December 2015

Published Online First 14 January 2016

Emerg Med J 2016:33:442-443.

doi:10.1136/emermed-2015-205536

\section{REFERENCES}

1 Mathias S, Nayak US, Isaacs B. Balance in elderly patients: the "get up-and-go" test. Arch Phys Med Rehabil 1986;67:387-9.

2 Department of Health. Urgent care pathways for older people with complex needs. London: Crown Copyright, 2007.

3 British Association of Occupational Therapists. OT Helps You. 2011. http://www.baot.org.uk/ ot-helps-you/ot-helpd-you (accessed 12 Dec 2011).

4 James K. The lived experience of occupational therapists in Accident and Emergency Departments in Scotland [Professional Doctorate Thesis]. Glasgow: Glasgow Caledonian University, 2014 